\title{
A Review Paper on Biomimetic Calcium Phosphate Coatings
}

\author{
X. Lin ${ }^{1,2,}$, K. de Groot ${ }^{1}$, D. Wang ${ }^{1}$, Q. Hu ${ }^{3}$, D. Wismeijer ${ }^{1}$ and Y. Liu ${ }^{1, *}$ \\ ${ }^{I}$ Department of Oral Implantology, Academic Centre of Dentistry Amsterdam (ACTA), VU University and University of \\ Amsterdam, Amsterdam, The Netherlands \\ ${ }^{2}$ Department of Orthodontics, Affiliated Stomatological Hospital of Medical School, Nanjing University, Nanjing, China \\ ${ }^{3}$ Department of Oral and Maxillofacial Surgery, Affiliated Stomatological Hospital of Medical School, Nanjing \\ University, Nanjing, China
}

\begin{abstract}
Biomimetic calcium phosphate coatings have been developed for bone regeneration and repair because of their biocompatibility, osteoconductivity, and easy preparation. They can be rendered osteoinductive by incorporating an osteogenic agent, such as bone morphogenetic protein 2 (BMP-2), into the crystalline lattice work in physiological situations. The biomimetic calcium phosphate coating enables a controlled, slow and local release of BMP-2 when it undergoes cell mediated coating degradation induced by multinuclear cells, such as osteoclasts and foreign body giant cells, which mimics a physiologically similar release mode, to achieve sustained ectopic or orthotopic bone formation. Therefore, biomimetic calcium phosphate coatings are considered to be a promising delivery vehicle for osteogenic agents. In this review, we present an overview of biomimetic calcium phosphate coatings including their preparation techniques, physico-chemical properties, potential as drug carrier, and their pre-clinical application both in ectopic and orthotopic animal models. We briefly review some features of hydroxyapatite coatings and their clinical applications to gain insight into the clinical applications of biomimetic calcium phosphate coatings in the near future.
\end{abstract}

Keywords: Animal model, biomimetic, calcium phosphate coating, clinical application, drug delivery, hydroxyapatite, osseoconduction, osseoinduction, pre-clinical study,

\section{INTRODUCTION}

Success in dental and orthopaedic implantology relies greatly on the surface modification related to osteoconductivity and osteoinductivity. By coating their surfaces with a layer of calcium phosphate, huge improvements have been achieved in the osteoconductivity of implants [1]. But the methods employed to deposit a calcium phosphate $(\mathrm{CaP})$ layer on the surface of implants, such as electrochemical deposition, sputter coating, plasma spraying, high velocity oxy-fuel spraying, sol-gel deposition, electrophoretic deposition, ion-assisted deposition, hot isostatic pressing and pulsed laser deposition [2-4], are all under physical conditions that are highly non-physiological, including higher temperatures. These high temperatures preclude the incorporation of a biological agent such as an osteogenic growth factor. Hence in most cases, biological agents can only be absorbed directly onto the surface of implants [5-8].

Recently attempts have been made to deposit layers of calcium phosphate on the surfaces of metal implants under more physiological or "biomimetic" conditions of temperature and $\mathrm{pH}$ [9-12]. The merit of the biomimetic coating technique is that osteoinductivity could be obtained

*Address correspondence to the author at the Department of Oral Implantology, Academic Centre of Dentistry Amsterdam (ACTA), VU University and University of Amsterdam, Amsterdam, The Netherlands; Tel: +31020 5980626; Fax: +31020 5980333; E-mail: y.liu@acta.nl through the co-precipitation with an osteogenic agent, the biological activity of which can be preserved through incorporation into the crystalline latticework of a biomimetic coating $[12,13]$. A depot of such an agent incorporated into the coating is liberated gradually [14] and in a cell-mediated mode over a period of several weeks [15]. Osteogenic activity can be induced and sustained efficiently under these conditions in both ectopic and orthotopic sites in animal models $[14,16]$. Biomimetic coatings have a great potential as a carrier for a drug in orthopedics as well as in maxillofacial surgery.

\section{BIOMIMETIC CALCIUM PHOSPHATE COATINGS}

Biomimetic calcium phosphate coatings were first developed by Kokubo [17] and his colleagues in 1990. It involved the nucleation and formation of bone-like crystals on a pretreated substratum by immersing it in a supersaturated solution of $\mathrm{CaP}$ under physiological conditions of temperature $\left(37^{\circ} \mathrm{C}\right)$ and $\mathrm{pH}(7.4)$. The method has been improved and refined by several groups of researchers [9, 11, 18-20], and an extensive evaluation as well as pre-clinical studies have been made [21, 22]. Recently a biomimetic calcium phosphate bone substitute has been developed based on biomimetic calcium phosphate coating [23, 24]. 


\subsection{Biomimetic Calcium Phosphate Coating Techniques}

The biomimetic coating technique consists of two basic steps: the deposition of amorphous calcium phosphate (ACP) at the surface of the substrates and subsequent deposition of coatings with or without protein on ACP [25]. Quite a few materials such as metallic carriers $[9,26]$, organic polymers [22] and deproteinized bovine bone (DBB) granules [21] could be biomimetically coated with a layer of calcium phosphate using this two phase biomimetic coating technique without any extra surface modification. The physico-chemical and morphological properties of the coatings were found to be independent of the surface geometry, the surface chemistry, or of the 3-dimensional structures of the underlying material [27].

\subsubsection{Formation of Primary Amorphous Calcium Phosphate Coatings}

ACP coatings on biomaterials were achieved under high nucleation conditions, in which crystal growth was inhibited by the presence of magnesium ions $(7.5 \mathrm{mM})$. Biomaterials were soaked in $5 \times$ concentrated simulated body fluid (SBF) for $24 \mathrm{~h}$ at $37^{\circ} \mathrm{C}$ (Table 1), the $\mathrm{pH}$ of which had been first adjusted to 6.5 by passing gaseous carbon dioxide (flow rate: $650 \mathrm{~mL} / \mathrm{min}$ ) and had risen to 8 at the end of this period. The coated biomaterials were rinsed in an ultrasonic cleaner with demineralized water for $10 \mathrm{~min}$ and then air dried overnight at ambient temperature. A thin (1-3 $\mu \mathrm{m}$ thick), dense and amorphous layer of calcium phosphate was coated uniformly on the surface of biomaterials prepared in this way. The calcium phosphate layer can diffract natural light and forms a multicolored fringe, hence the name "rainbow coating" [11]. Environmental scanning electron microscopy (ESEM) and energy-dispersive X-ray (EDX) examinations of the $\mathrm{ACP}$ showed that a dense and uniform $\mathrm{CaP}$ film (ACP coating) was deposited on the substrates. This layer is composed of spherical $\mathrm{CaP}$ globules about $0.1 \mu \mathrm{m}$ in diameter [19].

\subsubsection{Formation of Biomimetic Carbonated Apatite Coatings}

ACP-coated substrates were soaked in the metastable SBF solution (Table 1) for $24 \mathrm{~h}$ [28]. The original coating is then partially dissolved in the solution and transformed into carbonated apatite (BCA). When the ACP coating dissolves, it can initiate the deposition of a BCA coating and this results in a slight decrease of the solution $\mathrm{pH}$ [19]. In this step, BCA can be obtained by adjusting the concentration of inorganic elements or the temperature in the solution (Table 1) $[10,29]$.

\subsubsection{Formation of Biomimetic Octacalcium Phosphate Coatings}

After deposition of a ACP coating, an octacalcium phosphate $(\mathrm{OCP})\left[\mathrm{Ca}_{8} \mathrm{H}_{2}\left(\mathrm{PO}_{4}\right)_{6} \cdot 5 \mathrm{H}_{2} \mathrm{O}\right]$ coating is produced biomimetically by soaking the ACP-coated substrates in a supersaturated calcium phosphate solution (Table 1) for $48 \mathrm{~h}$ at $37^{\circ} \mathrm{C}$. The samples are then freeze dried. Osteogenic agents such as bone morphogenetic protein-2 (BMP-2) could be incorporated into the crystal layers at a given concentration [11]. The OCP crystals grow directly on top of the ACP coating. The formation of the OCP coating is a dynamic process involving the partial dissolution of the ACP coating and the reprecipitation of the crystalline phase from the solution [19].

\subsubsection{Incorporation of Proteins Into Biomimetic Calcium Phosphate Coatings}

Proteins and other biological agents can be incorporated into OCP coatings. Bovine serum albumin (BSA) was used as a model protein, in place of more expensive proteins such as BMP-2, to study the coating properties as well as the kinetics of the protein release. Different concentrations of BSA were added into the solution used for forming the coating $[11,15,24,30]$. BMP-2 and parathyroid hormone $(\mathrm{PTH})$ have been biomimetically incorporated into $\mathrm{CaP}$ coatings to improve osseointegration of implants in vivo and the characteristics of the coatings were also evaluated [14, 16, 31-37].

\subsection{Characteristics of Biomimetic Calcium Phosphate Coatings}

\subsubsection{Coating Thickness}

The thickness of the OCP coating was measured using a magnetic induction probe and varied between 30 and $50 \mu \mathrm{m}$ [11]. This was corroborated by an in vitro study by Wang et al. [29], who observed OCP and BCA coatings with an environmental scanning electron microscope (ESEM). The ESEM micrographs revealed that the OCP coating exhibited a relatively flat surface composed of sharp plate like crystals, $30 \mu \mathrm{m}$ long and $0.2 \mu \mathrm{m}$ wide. The BCA coating displayed a relatively rough surface composed of $\mathrm{CaP}$ globules about $20-30 \mu \mathrm{m}$ in diameter composed of small crystals about 1-2 $\mu \mathrm{m}$ in size. These findings agree with the results in Barrere's experiment [26] in which the BCP and the OCP coating were applied to porous metal implants. The ESEM micrographs showed that both coatings were homogeneous and had a similar thickness of approximately $20-30 \mu \mathrm{m}$.

Table 1. Inorganic ion composition (mmol/l) of SBF, supersaturated CaP solutions [10, 38].

\begin{tabular}{|c|c|c|c|c|c|c|c|c|c|}
\hline & $\mathbf{N a}^{+}$ & $\mathbf{K}^{+}$ & $\mathbf{M g}^{2+}$ & $\mathbf{C a}^{2+}$ & $\mathbf{C l}^{-}$ & $\mathbf{H P O}_{4}^{2-}$ & $\mathbf{S O}_{\mathbf{4}}^{2-}$ & $\mathbf{H C O}_{3}^{-}$ & $\mathbf{p H}^{-}$ \\
\hline \hline SBF & 142.0 & 5.0 & 1.5 & 2.5 & 147.8 & 1.0 & 0.5 & 4.2 & 7.4 \\
\hline ACP & 733.5 & - & 7.5 & 12.5 & 720.0 & 5.0 & - & 21.0 & 5.8 \\
\hline BCA & 733.5 & - & 1.5 & 12.5 & 720.0 & 5.0 & - & 10.0 & 5.8 \\
\hline OCP & 140.5 & - & - & 4.0 & 144.5 & 2.0 & - & - & 7.4 \\
\hline
\end{tabular}


Heterogeneous nucleation of $\mathrm{CaP}$ crystals was initiated by an increase in supersaturation of the SBF solution around the substrate. After soaking for $2 \mathrm{~h}$ in SBF solution, morphological changes were found in the initial ACP coating in which $\mathrm{CaP}$ globules increased in size and were covered by crystals smaller than $5 \mu \mathrm{m}$. As soaking continued, these crystals grew larger and the globules were no longer visible. After 48 hours of soaking, these sharp crystal plates were approximately $20-30 \mu \mathrm{m}$ long and $0.1 \mu \mathrm{m}$ thick [19].

\subsubsection{Composition and Geometry of Coatings}

The BCA coating was $65 \%$ crystalline and consisted of a carbonate apatite that is closely similar to the natural bone mineral. The OCP coating was $100 \%$ crystalline (Fig. 1A) and consisted of octacalcium phosphate crystals [OCP, $\left.\mathrm{Ca}_{8}\left(\mathrm{HPO}_{4}\right)_{2}\left(\mathrm{PO}_{4}\right)_{4} \cdot 5 \mathrm{H}_{2} \mathrm{O}\right]$ that grew perpendicularly to the substrate [39]. This finding is supported by Barrere's work [28] in which not only the OCP coating, but also the BCA coating grew perpendicularly to the Ti6A14V substrate. The coatings were composed entirely of straight, plate like crystallites with sharp edges and contained typical OCP crystals when the coatings were prepared without incorporating BSA. As the solution concentration of BSA increased, the coatings gradually took on the characteristics of carbonated apatite and the crystals became progressively smaller, showing an obvious curvature, and became packed more densely. When the concentration of BSA was increased, a mixture of OCP and carbonated apatite (CAP) was formed, and their bulk composition and preferential crystallographic orientation underwent a gradual transformation, indicating that the coatings were becoming less crystalline [12].

\subsubsection{Mechanical Strength}

The micro-scratch test revealed that the calcium phosphate coatings prepared in the presence of protein possessed a higher mechanical strength than those prepared without protein [32]. When implants were inserted into an artificial bone, a great resistance to the shear forces was found in the calcium phosphate coating into which the model protein BSA was incorporated [30]. One explanation is that the proteins (BSA or BMP-2), which are co-precipitated with the inorganic ions to form the coating, influenced the growth of the crystalline latticework. Consequently, the crystals that are composed of the calcium and phosphate ions were smaller and more densely packed in the presence of these proteins than those that develop in its absence [12].

\subsubsection{Coating Degradation and BMP-2 Release}

An optimum CaP coating should degrade at a rate similar to that of bone formation and it should disappear completely after bone healing. The total resorption of the CaP coating served to avoid a possible weakening that would occur within the CaP coating remaining at the interface [28].

ACP, CAP, and OCP coatings were tested for 7 days in vitro in a murine bone marrow cell culture enriched with osteoclast to study their response to osteoclasts [10]. Resorption lacunae typical of osteoclastic resorption were not found on the ACP coating. In contrast to this, the resorption of CAP coating was very clear with the typical scalloped resorption pits or lacunae. The OCP coating did not reveal any clear resorption pits, but the coating morphology changed, showing many visible irregularities in the coating and attacked areas. The most likely reason for this phenomenon is that the surface morphology of the irregular OCP coatings prohibits the formation of sharp resorption lacunae even though the coating can be attacked by osteoclasts. Another explanation could be that, in contrast to CAP and dentine, OCP does not contain carbonate which may play an important part in osteoclastic resorption [40]. The lack of carbonate in OCP and the higher dissolvability of the OCP coatings could also be an important factor [41]. As OCP coatings are homogeneous throughout their total thickness they should dissolve gradually and completely over time during the implantation [16].

The OCP coating consist of large crystals oriented vertically to the substrate surface thus exhibiting a network structure open to the surrounding body fluid, while the BCA show smaller and denser crystals. Because in the former case much more surface will be exposed to the body fluid, a higher reactivity might be expected between the OCP coating and its environment than for the BCA coating. On the other hand, BCA crystallinity is remarkably lower than $\mathrm{OCP}$, which can be ascribed to the distortions and
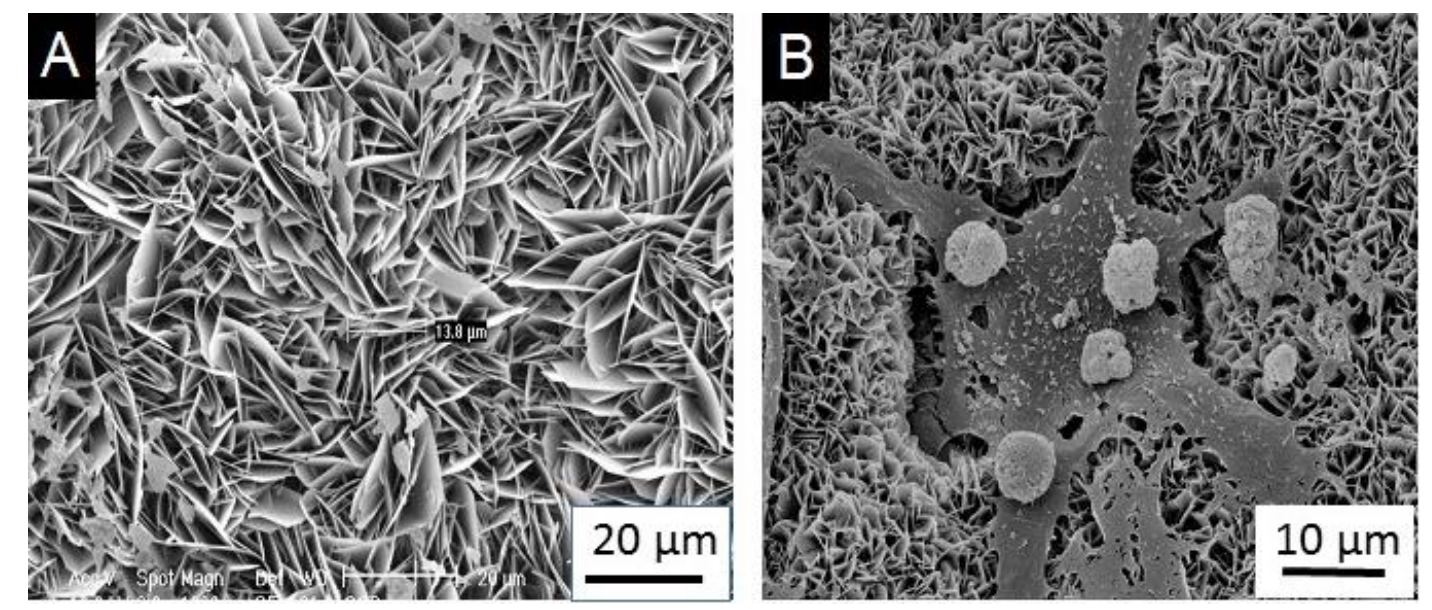

Fig. (1). SEM micrographs of OCP coating (A) and osteoclastic resorption of OCP coating with resorption lacunae (B). 
deficiencies produced by the incorporation of carbonate in the apatite lattice. This lower crystallinity would imply a faster dissolution of BCA compared with OCP [28].

When Ti6A14V samples coated with OCP and BCA were implanted subcutaneously in male Wistar rats for 4 weeks, Fourier transform infrared spectroscopy (FTIR) revealed structural changes in the OCP coating that evolved into a CAP. The mineral structure remained the same for the BCA coating. These results indicated that organic compounds of the surrounding body fluid became a part of the coating during the subcutaneous implantation [28]. However, when the OCP coating was doped with BMP-2, an obvious degradation could be found from 3 to 5 weeks in vivo [14]. A possible reason is that osteogenic activity may be promoted by releasing BMP-2 from the degrading inorganic matrix. Then osteoclasts participate in the degradation and a high rate of degradation of the coating could be observed (Fig. 1B). This resulted presumably from the synergistic resorption of foreign body giant cells and osteoclasts [42-44].

\section{BIOMIMETIC CALCIUM PHOSPHATE COATINGS AS CARRIER FOR DRUGS}

A great effort has been made mainly to improve biocompatibility and biodegradability of metal implants by coating them with layers of calcium phosphate under physiological or 'biomimetic' conditions of temperature and $\mathrm{pH}[11,12,45-48]$. An additional merit of the biomimetic way is that molecules with biological activity, such as osteogenic agents, can be co-precipitated with the inorganic components. Consequently, the proteins are genuinely incorporated into the crystal lattice network and not merely deposited on its surface. By becoming an integral part of the calcium phosphate coatings, the protein molecules are released not in a single burst (which happens when superficially adsorbed), but gradually. This bodes well for a sustained osteogenic effect at the implantation site. The bioactivity of these osteogenic agents could be preserved because of the physiological conditions when the coating is formed [31]. This method is simple to perform, it is cost efficient and it can be used even for non-conductive, heatsensitive and porous materials of large sizes and with complex surface geometries. This means that biomimetic coating has a great potential as a drug carrying system.

The drug delivery mode played an important role in osseoinductive efficacy, which has been proven in an in vivo study [33]. BMP-2 molecules incorporated in the coating are liberated via a cell-mediated procedure, viz., during the osteoclastic degradation of the inorganic layer. This process is similar to physiological bone remodeling, by virtue of growth factors being liberated from the bone matrix during its degradation. This appears to be the most efficient way to induce bone formation without overstimulating bone resorption.

In an ectopic rat model, approximately $60 \%$ of both the biomimetic coating and the incorporated BMP-2 was degraded during the 5 weeks implantation period [14]. Therefore, approximately $40 \%$ of the original coating material and the BMP-2 incorporated in it would continue to be released slowly to induce sustained bone formation for several weeks after the end of the experiment. A similar quantity of the superficially adsorbed BMP-2 was released in a few days through a single burst and elicited only a transient, sporadic and abortive osteogenic response. This implies that a lower but sustained pharmacological level of the drug is osteogenically more potent and efficient than a higher dose delivered over a short time span.

Biomimetic CaP coatings can carry not only bone growth factors but also antibiotics. Different antibiotics were incorporated into a carbonated hydroxyapatite (CHAp) coating, and their release and effectiveness against bacterial growth were studied in vitro [49]. This suggested that certain antibiotics could bind with calcium resulting in a better incorporation into the CHA coating and a slower release rate. This method might be applied to prevent infections after surgery and to promote the bonding of orthopaedic devices with bone.

\section{PRE-CLINICAL APPLICATIONS}

\subsection{Ectopic Model}

The osseoinductive potential of titanium alloy implants containing BMP-2 was investigated using a gold standard ectopic ossification rat model [14]. The net weekly rate of bone formation, the rate of the degradation of the coating, and the spatial extent of bone formation induced by BMP-2 was quantified over a period of 5 weeks. The use of a biomimetic coating showed properties that were highly biocompatible, osseoconductive, and osseoinductive. BMP-2 was released gradually, inducing a sustained bone formation at the implant. Other research using the same ectopic rat model indicated that when BMP-2 was incorporated into calcium phosphate coatings, it was more efficient for bone formation than surface adsorption onto either a calcium phosphate coating or an uncoated implant. The efficacy of the biomimetic coating was compromised by additional surface adsorption of BMP-2 [33]. This may be attributed to the initial burst release of BMP-2 from the adsorbed pool because the transient high concentration of BMP-2 could encourage the recruitment and activation of osteoclasts, thus enhancing bone resorption [50].

In an ectopic rat model, the incorporated-BMP-2 group provoked less inflammation than the adsorbed-BMP-2 group together with the no BMP-2 group. The areal coverage of coatings with foreign body giant cells was lower after 5 weeks implantation in the incorporated-BMP-2 group than in other groups [14]. This finding was corroborated by an in vivo study by $\mathrm{Wu}$ et al. [22]. They investigated the inflammation produced by four polymers (collagen, Ethisorb $^{\mathrm{TM}}$, PLGA and Polyactive ${ }^{\circledR}$ ) with either an adsorbed depot of BMP-2, which showed a fast release or a depot with an incorporated calcium phosphate coating, which showed a slow release. Less inflammation was found when the polymeric material bore biomimetic coatings containing BMP-2, than when the drug was adsorbed superficially onto the depot.

A similar result was obtained when BMP-2 was incorporated into calcium phosphate coating on deproteinized bovine bone (DBB) granules [21, 24, 51]. One explanation for this is that an increase of the osteogenic 
activity can dampen inflammation by restraining the participation of foreign body giant cells. The effect is regulated by osteopontin, which inhibits the multinucleation, by binding the CD44 surface receptors on macrophages [52].

According to a recent study [53], the volume of new bone formation on discs bearing a depot of BMP-2 incorporated in a coating was similar whether they are mechanically stabilized or not stabilized at all. When BMP-2 was adsorbed superficially, the volume of bone was 10 times higher when mechanically stabilized than when it was not. These findings indicate that delivery of BMP-2 in a physiological way (slow release), viz., via cell-mediated degradation, is not affected by the presence or absence of a mechanically stable environment.

\subsection{Orthotopic Model}

Some experiments [16, 54] have been carried out to assess the effect of BMP-2 and its mode of delivery on the osseoinductivity in dental implants, inserted into the maxillae of adult miniature pigs. They found that the osteoinductivity of implant surfaces was most severely damaged when BMP-2 was superficially adsorbed on implant surfaces either coated with calcium phosphate or uncoated. Osteoinductivity was impaired least when BMP-2 was incorporated into a calcium phosphate coating. These results were corroborated by another experiment in rats [33] that indicated that liberation of BMP-2 slowly and gradually, which mimics the release of growth factors from the bone matrix under physiological conditions, is the best mode of drug delivery. The therapeutic effectiveness of the biomimetic coating method in combination with DBB granules was investigated recently for the restoration of critical-size bone defects in sheep [23]. Four weeks after surgery, more newly formed bone could be found in the groups of DBB mixed with autologous bone or with BMP-2 incorporated in a coating than in the other groups with DBB. Eight weeks after surgery, the volume of the newly formed bone in the group of DBB with BMP-2 incorporated in a coating was greatest among the groups with DBB and it was comparable with the autologous bone group. This suggests that the capacity of BMP-2 to induce and maintain local bone formation in critical-sized bone defects could be influenced by the method of delivery. The biomimetic coating technique could also be applied to the parathyroid hormone (PTH). Yu et al. evaluated the osseointegration of a $\mathrm{CaP}$ coating incorporated with PTH on titanium implants which were inserted into the tibiae of mice. They found that peri-implant bone formation was highly dependent on the dosage of PTH [36].

\section{HYDROXYAPATITE COATING AND ITS CLINICAL APPLICATIONS}

Crystalline hydroxyapatite (HAp), in the form of $\mathrm{Ca}_{10}\left(\mathrm{PO}_{4}\right)_{6}(\mathrm{OH})_{2}$ with a $\mathrm{Ca} / \mathrm{P}$ ratio of 1.67 , is the major mineral component of natural bone [55, 56]. An HAp coating can improve the attachment and proliferation of osteoblast cells [57] and the main advantages of HAp are its good osteoconductivity, osteoconductivity, slow biodegradability and biocompatibility [58]. Sintered HA showed excellent biocompatibility with bone, skin, muscle and gums [59]. In addition, HA is thermodynamically the most stable calcium phosphate in a physiological environment $(\mathrm{pH} \geq 5.4)$ and it is commonly used as a coating for an implant to stimulate bone formation around it [60]. During osseointegration, a strong bond between the bone and a hydroxyapatite-coated prosthesis was established in the interface between the implant and HAp [61] and the shear strength of interface between bone and implant in HA-coated titanium was 5 to 8 times stronger than that of titanium without the coating [62]. When compared with some bone substitutes, such as metallic implants or allografts, HAp showed a strong affinity to host hard tissues through its chemical bonding with the host tissue [63]. Histological studies in dogs showed that cylindrical implants coated with HAp gave a faster bone formation after 1 and 4 months than grit-blasted implants without a coating [64, 65]. At the surface of titanium blade implants coated with HAp, a direct contact with the bone could be observed after 6 months in the healed sites of the molar region of rhesus monkeys [66].

Although titanium prostheses coated with hydroxyapatite layers by plasma spraying have been used in joint reconstruction and have provided promising results [67-69], the plasma spraying technique has some drawbacks that cannot be neglected. The extremely high temperatures exceeding $10,000^{\circ} \mathrm{C}$ involved in producing the hydroxyapatite coatings made the incorporation of biologically active molecules impossible. The mineral layers are composed of large, partially molten hydroxyapatite granules that are prone to delamination. In addition, because of their surface roughness and hydrophilicity HAp-coated implants are more susceptible to bacteria colonization than uncoated titanium implants [70]. The work from Wolinsky et al. demonstrated in vitro that specific bacteria, such as Actinomyces viscosus, can adhere more easily to HA powder than to titanium powder $[71,72]$.

Although a variety of coatings have been developed to enhance osseointegration in pre-clinical studies, only a few of them have been applied clinically. These include HAp and bisphosphonate coatings [73]. HAp coatings could dramatically improve the osseointegration and the survival rate of implants when placed in a compromised bone condition. Therefore, on the one hand, HAp coatings were most extensively applied clinically to hip implants, dental implants and knee prostheses [74]. On the other hand, HApcoated implants showed few statistically significant differences when compared with uncoated implants as long as the surrounding bone tissue exhibited sufficient quantity and quality of the bone to achieve initial stability. This phenomenon was observed in dental implants [75, 76], hip [77-79] and knee implants [80].

According to the classification of Lekholm and Zarb [81], bone quality is divided into four types (I, II, III and IV). The initial stability becomes more difficult to achieve as the bone quality moves from type I to type IV. After studying 673 Steri-Oss implant system $\left(\right.$ Denar $^{\circledR}$ ) during a 5-year period, Saadoun and LeGall [82] suggested that the implant design should be based on the anatomical region, bone quality and implant lengths. Furthermore, the closer the bone quality is to type IV, the greater the indication is for HApcoated titanium cylinders. The effect of the coating on the 
implant survival rate as a function of bone quality has been studied [83]. HAp-coated implants had a total failure rate of $3.9 \%$ during 36 months for all bone qualities combined, whereas uncoated implants had a failure rate of $13.4 \%$. The highest failure rates for uncoated implants were in bone qualities III and IV (19.1\% and $25.5 \%$, respectively). Therefore, HAp-coated implants are more appropriate for patients with a compromised bone quality, whereas HApcoated implants should not be recommended for patients with an acceptable bone quality.

Albrektsson et al. $[84,85]$ have argued that HAp coatings are unstable, more susceptible to bacterial infection, may be predisposed to a rapid bone breakdown and they do not show any significant advantages over titanium implants [83]. It was also discovered the HAp is unable to improve the longterm outcome of bipolar hemiarthroplasty. This is because in the HAp-coated prostheses that were initially well fixed, the sealing effect of a HAp coating creates high concentrations of polyethylene in the limited joint space. This results in massive proximal femoral osteolysis. HAp-coated implants should be applied cautiously to patients because of its negative effects on bone formation. Consequently, a HAp coating introduces a new failure mechanism and HAp coated implants should only be recommended for patients with compromised bone quality. Dental implants coated with bisphosphonates designed to be locally released were also studied in clinical trials [73]. The positive results make them promising candidates for dental implants and orthopaedic surgery in osteoporotic bone.

\section{DISCUSSION}

Until recently, deposition layers of calcium phosphate upon the surfaces of metal implants under physical conditions were highly non-physiological. Although calcium phosphate coatings improve the osteoconductivity of metal implants, they do not make them osseoinductive. Osteoinductive properties can be conferred on them by introducing an osteogenic growth factor into the system [6, 86-89]. Rendering calcium phosphate layers osseoinductive is the problem to be solved by the next generation of implants. For this purpose, a great effort has been expended to functionalize such coatings with osteogenic agents. Among several others, bone morphogenetic protein-2 (BMP2) has proved to be the one with the most potent osseoinductive property $[90,91]$.

The methods mentioned here for depositing layers of calcium phosphate upon metal implant surfaces were applied under such non-physiological conditions that they preclude the incorporation of osteogenic growth factors. These agents can be only deposited superficially upon pre-formed coatings, either by adsorption [88, 92, 93], by chemical treatment [94] or by binding with biofunctional proteins [95]. Although bone formation can be activated by such techniques, the pharmacological dose applied in this way is extremely high because the adsorbed BMP-2 is released very rapidly [96, 97] and most of it diffuses away before it can be effective. Apart from the unnecessary cost of such waste, the transient and very high concentrations of BMP-2 can trigger undesirable side effects, such as overstimulation of local bone resorption $[33,98]$, overstimulation of bone formation at both local and distant sites, and augmentation of local neuropathy $[99,100]$. In contrast to this, biomimetic coatings enable a controlled, local and slow release of BMP-2 through three mechanisms, (i) initial burst release controlled by diffusion, (ii) release controlled chemically by coating dissolution and (iii) cell (osteoclast)-mediated release. A biomimetic coating can prolong the degradation in vivo of those biomaterials that degrade easily but not of those that do not. Coatings incorporated with BMP-2 induce remarkably more efficiently an energetic regeneration of bone and bone marrow tissues than coatings merely with adsorbed BMP-2. Moreover, foreign body response of the host to the implanted biomaterials could be significantly reduced in many ways.

Future studies of this technique should concentrate on several aspects such as the preparation of the coating on voluminous 3 dimensional scaffolds, the mechanisms of immunosuppression and the adoption of more potent forms of BMPs. We have proven that functionalized biomimetic calcium phosphates are promising candidates for bone fillers [24].

One potential disadvantage associated with biomimetic coatings is the low rate with which proteins are incorporated into calcium phosphate. A large quantity of the drug was needed to incorporate just a small amount within the inorganic latticework [14]. During the biomimetic approach only 3 to $15 \%$ of the proteins in the supersaturated calcium phosphate solution could be incorporated into the $\mathrm{CaP}$ coating $[31,33]$. An improvement in the biomimetic coating technique for enhancing the rate of incorporating the protein is needed to broaden its clinical application [35].

\section{CONCLUSION}

The biomimetic technique to coat implants with a layer of calcium phosphate can be applied to biological functionalization of implant coatings with the osteogenic agent BMP-2. The ultimate aim of this research is to develop a slow release delivery system for osteogenic agents to promote local bone formation around dental or orthopaedic implants and thereby expediting their osseointegration. Since the process is carried out at a temperature and $\mathrm{pH}$ of physiological conditions, protein molecules such as BMP-2 can be and have been incorporated into the inorganic crystal latticework at the time of its formation. When the inorganic components of the coating are dissolved, the protein molecules remain as a self-supporting scaffold, which can then be remineralized. The incorporated protein enhances the mechanical strength of the coating which is necessary to withstand the high shear forces generated during surgical implantation and it also slows down its rate of dissolution.

The slow release of BMP-2 incorporated in a coating has been confirmed. The osseoinductive potency of coatingincorporated BMP-2 has been established both in vitro and in vivo. Currently, the possibility of biomimetic $\mathrm{CaP}$ coating and functionalizing bone substitutes for filling and repairing large osseous defects is being studied. A clinical trial is underway for the treatment of some cases involving repairing a bone defect. 


\section{CONFLICT OF INTEREST}

The authors confirm that this article content has no conflict of interest.

\section{ACKNOWLEDGEMENTS}

We would like to thank Prof. Dr. Tony G. Hearn for his English editing as a native speaker and the scientific input of this publication.

\section{REFERENCES}

[1] M. Wong, J. Eulenberger, R. Schenk, and E. Hunziker, "Effect of surface topology on the osseointegration of implant materials in trabecular bone," J. Biomed. Mater. Res., vol. 29, pp. 1567-75, 1995.

[2] J. G. Wolke, K. de Groot, and J. A. Jansen, "Subperiosteal implantation of various RF magnetron sputtered Ca-P coatings in goats," J. Biomed. Mater. Res., vol. 43, pp. 270-6, 1998.

[3] J. G. Wolke, K. de Groot, and J. A. Jansen, "In vivo dissolution behavior of various RF magnetron sputtered Ca-P coatings," $J$. Biomed. Mater. Res., vol. 39, pp. 524-30, 1998.

[4] J. G. Wolke, K. van Dijk, H. G. Schaeken, K. de Groot, and J. A. Jansen, "Study of the surface characteristics of magnetron-sputter calcium phosphate coatings," J. Biomed. Mater. Res., vol. 28, pp. 1477-84, 1994.

[5] J. O. Hollinger, J. M. Schmitt, D. C. Buck, R. Shannon, S. P. Joh, H. D. Zegzula, and J. Wozney, "Recombinant human bone morphogenetic protein-2 and collagen for bone regeneration," $J$. Biomed. Mater. Res., vol. 43, pp. 356-64, 1998.

[6] T. Kawai, A. Mieki, Y. Ohno, M. Umemura, H. Kataoka, S. Kurita, M. Koie, T. Jinde, J. Hasegawa, and M. R. Urist, "Osteoinductive activity of composites of bone morphogenetic protein and pure titanium," Clin. Orthopaed. Related Res., pp. 296-305, 1993.

[7] T. Noshi, T. Yoshikawa, Y. Dohi, M. Ikeuchi, K. Horiuchi, K. Ichijima, M. Sugimura, K. Yonemasu, and H. Ohgushi, "Recombinant human bone morphogenetic protein-2 potentiates the in vivo osteogenic ability of marrow/hydroxyapatite composites," Artif. Organs, vol. 25, pp. 201-8, 2001.

[8] U. Ripamonti, L. Yeates, and B. van den Heever, "Initiation of heterotopic osteogenesis in primates after chromatographic adsorption of osteogenin, a bone morphogenetic protein, onto porous hydroxyapatite," Biochem. Biophys. Res. Common., vol. 193, pp. 509-17, 1993.

[9] F. Barrere, P. Layrolle, C. A. van Blitterswijk, and K. de Groot, "Biomimetic calcium phosphate coatings on Ti6AI4V: a crystal growth study of octacalcium phosphate and inhibition by $\mathrm{Mg}^{2+}$ and $\mathrm{HCO}_{3}, "$ Bone, vol. 25, pp. 107S-111S, 1999.

[10] S. Leeuwenburgh, P. Layrolle, F. Barrere, J. de Bruijn, J. Schoonman, C. A. van Blitterswijk, and K. de Groot, "Osteoclastic resorption of biomimetic calcium phosphate coatings in vitro," $J$. Biomed. Mater. Res., vol. 56, pp. 208-15, 2001.

[11] Y. Liu, P. Layrolle, J. de Bruijn, C. van Blitterswijk, and K. de Groot, "Biomimetic coprecipitation of calcium phosphate and bovine serum albumin on titanium alloy," J. Biomed. Mater. Res., vol. 57, pp. 327-35, 2001.

[12] H. B. Wen, J. R. de Wijn, C. A. van Blitterswijk, and K. de Groot, "Incorporation of bovine serum albumin in calcium phosphate coating on titanium," J. Biomed. Mater. Res., vol. 46, pp. 245-52, 1999.

[13] Y. Liu, E. B. Hunziker, P. Layrolle, C. Van Blitterswijk, P. D. Calvert, and K. de Groot, "Remineralization of demineralized albumin-calcium phosphate coatings," J. Biomed. Mater. Res. Part A, vol. 67, pp. 1155-62, 152003.

[14] Y. Liu, K. de Groot, and E. B. Hunziker, "BMP-2 liberated from biomimetic implant coatings induces and sustains direct ossification in an ectopic rat model," Bone, vol. 36, pp. 745-57, 2005.

[15] E. Wernike, W. Hofstetter, Y. Liu, G. Wu, H. J. Sebald, D. Wismeijer, E. B. Hunziker, K. A. Siebenrock, and F. M. Klenke, "Long-term cell-mediated protein release from calcium phosphate ceramics," J. Biomed. Mater. Res. Part A, vol. 92, pp. 463-74, 2010.
[16] Y. Liu, L. Enggist, A. F. Kuffer, D. Buser, and E. B. Hunziker, "The influence of BMP-2 and its mode of delivery on the osteoconductivity of implant surfaces during the early phase of osseointegration," Biomaterials, vol. 28, pp. 2677-86, 2007.

[17] T. Kokubo, S. Ito, Z. T. Huang, T. Hayashi, S. Sakka, T. Kitsugi, and T. Yamamuro, "Ca,P-rich layer formed on high-strength bioactive glass-ceramic A-W," J. Biomed. Mater. Res., vol. 24, pp. 331-343, 1990

[18] H. Y. Lin, Y. Liu, D. Wismeijer, W. Crielaard, and D. M. "Deng, "Effects of oral implant surface roughness on bacterial biofilm formation and treatment efficacy," Int. J. Oral Maxillofac. Implants, vol. 28, pp. 1226-31, 2013.

[19] F. Barrere, P. Layrolle, C. A. Van Blitterswijk, and K. De Groot, "Biomimetic coatings on titanium: a crystal growth study of octacalcium phosphate," J. Mater. Sci. Mater. Med., vol. 12, pp. 529-34, 2001.

[20] F. Barrere, C. A. van Blitterswijk, K. de Groot, and P. Layrolle, "Influence of ionic strength and carbonate on the Ca-P coating formation from SBFx5 solution," Biomaterials, vol. 23, pp. 192130, May 2002.

[21] G. Wu, E. B. Hunziker, Y. Zheng, D. Wismeijer, and Y. Liu, "Functionalization of deproteinized bovine bone with a coatingincorporated depot of BMP-2 renders the material efficiently osteoinductive and suppresses foreign-body reactivity," Bone, vol. 49, pp. 1323-30, 2011

[22] G. Wu, Y. Liu, T. lizuka, and E. B. Hunziker, "The effect of a slow mode of BMP-2 delivery on the inflammatory response provoked by bone-defect-filling polymeric scaffolds," Biomaterials, vol. 31, pp. 7485-93, 2010.

[23] T. Liu, G. Wu, D. Wismeijer, Z. Gu, and Y. Liu, "Deproteinized bovine bone functionalized with the slow delivery of BMP-2 for the repair of critical-sized bone defects in sheep," Bone, vol. 56, pp. 110-8, 2013.

[24] T. Liu, G. Wu, Y. Zheng, D. Wismeijer, V. Everts, and Y. Liu, "Cellmediated BMP-2 release from a novel dual-drug delivery system promotes bone formation," Clin. Oral Implants Res., vol. 25, no. 12, pp. 1412-1421, 2013.

[25] M. Stigter, K. de Groot, and P. Layrolle, "Incorporation of tobramycin into biomimetic hydroxyapatite coating on titanium," Biomaterials, vol. 23, pp. 4143-53, 2002.

[26] F. Barrere, C. M. van der Valk, R. A. Dalmeijer, G. Meijer, C. A. van Blitterswijk, K. de Groot, and P. Layrolle, "Osteogenecity of octacalcium phosphate coatings applied on porous metal implants," J. Biomed. Mater. Res. Part A, vol. 66, pp. 779-88, 2003.

[27] G. Wu, Y. Liu, T. Iizuka, and E. B. Hunziker, "Biomimetic coating of organic polymers with a protein-functionalized layer of calcium phosphate: the surface properties of the carrier influence neither the coating characteristics nor the incorporation mechanism or release kinetics of the protein," Tissue Eng. Part C, Methods, vol. 16, pp. $1255-65,2010$

[28] F. Barrere, C. M. van der Valk, R. A. Dalmeijer, C. A. van Blitterswijk, K. de Groot, and P. Layrolle, "In vitro and in vivo degradation of biomimetic octacalcium phosphate and carbonate apatite coatings on titanium implants," J. Biomed. Mater. Res. Part A, vol. 64, pp. 378-87, 2003.

[29] J. Wang, P. Layrolle, M. Stigter, and K. de Groot, "Biomimetic and electrolytic calcium phosphate coatings on titanium alloy: physicochemical characteristics and cell attachment," Biomaterials, vol. 25 , pp. 583-92, 2004.

[30] T. T. Hagi, L. Enggist, D. Michel, S. J. Ferguson, Y. Liu, and E. B. Hunziker, "Mechanical insertion properties of calcium-phosphate implant coatings," Clin. Oral Implants Res., vol. 21, pp. 1214-22, 2010.

[31] Y. Liu, E. B. Hunziker, P. Layrolle, J. D. De Bruijn, and K. De Groot, "Bone morphogenetic protein 2 incorporated into biomimetic coatings retains its biological activity," Tissue Eng., vol. 10, pp. 101-8, 2004.

[32] Y. Liu, E. B. Hunziker, N. X. Randall, K. de Groot, and P. Layrolle, "Proteins incorporated into biomimetically prepared calcium phosphate coatings modulate their mechanical strength and dissolution rate," Biomaterials, vol. 24, pp. 65-70, 2003.

[33] Y. Liu, R. O. Huse, K. de Groot, D. Buser, and E. B. Hunziker, "Delivery Mode and Efficacy of BMP-2 in Association with Implants," J. Dent. Res., vol. 86, pp. 84-89, 2007.

[34] Y. Liu, G. Wu, and K. de Groot, "Biomimetic coatings for bone tissue engineering of critical-sized defects," J. Royal Soc. Interface/ 
the R Soc, vol. 7 Suppl 5, pp. S631-47, Oct 62010.

[35] X. Yu, H. Qu, D. A. Knecht, and M. Wei, "Incorporation of bovine serum albumin into biomimetic coatings on titanium with high loading efficacy and its release behavior," J. Mat. Sci. Mat. Med., vol. 20, pp. 287-94, 2009.

[36] X. Yu, L. Wang, X. Jiang, D. Rowe, and M. Wei, "Biomimetic CaP coating incorporated with parathyroid hormone improves the osseointegration of titanium implant," J. Mat. Sci. Mat. Med., vol. 23, pp. 2177-86, 2012.

[37] X. Yu and M. Wei, "Preparation and evaluation of parathyroid hormone incorporated $\mathrm{CaP}$ coating via a biomimetic method," $J$. Biomed. Mater. Res.. Part B, Appl. Biomat., vol. 97, pp. 345-54, 2011.

[38] Y. Liu, K. de Groot, and E. B. Hunziker, "Osteoinductive implants: the mise-en-scene for drug-bearing biomimetic coatings," Ann. Biomed. Eng., vol. 32, pp. 398-406, 2004.

[39] B. F. Habibovic P, vAN Blitterswijk CA, de Groot K, Layrolle P., "<Biomimetic Hydroxyapatite Coating on Metal Implants.pdf>," $J$. Am. Ceram Soc., pp. 517-522, 2002.

[40] Y. Doi, H. Iwanaga, T. Shibutani, Y. Moriwaki, and Y. Iwayama, "Osteoclastic responses to various calcium phosphates in cell cultures," J. Biomed. Mater. Res., vol. 47, pp. 424-33, 1999.

[41] J. W. Zhang and G. H. Nancollas, "Kinetics and Mechanisms of Octacalcium Phosphate Dissolution at 37 Degrees-C," J. Phys. Chem., vol. 96, pp. 5478-5483, 1992.

[42] E. Filvaroff and R. Derynck, "Bone remodelling: a signalling system for osteoclast regulation," Curr. Bio.: CB, vol. 8, pp. R67982, 1998.

[43] T. Katagiri and N. Takahashi, "Regulatory mechanisms of osteoblast and osteoclast differentiation," Oral Dis., vol. 8, pp. 14759, 2002.

[44] K. Mostov and Z. Werb, "Journey across the osteoclast," Science, vol. 276, pp. 219-20, 111997.

[45] K. de Groot, "Hydroxylapatite coated implants," J. Biomed. Mater. Res., vol. 23, pp. 1367-71, 1989.

[46] K. de Groot, J. G. Wolke, and J. A. Jansen, "Calcium phosphate coatings for medical implants," Proceedings of the Institution of Mechanical Engineers. Part H, Journal of engineering in medicine, vol. 212, pp. 137-47, 1998.

[47] T. Kokubo, "Bioactive glass ceramics: properties and applications," Biomaterials, vol. 12, pp. 155-63, 1991.

[48] T. Kokubo, H. Kushitani, S. Sakka, T. Kitsugi, and T. Yamamuro, "Solutions able to reproduce in vivo surface-structure changes in bioactive glass-ceramic A-W," J. Biomed. Mater. Res., vol. 24, pp. 721-34, 1990.

[49] M. Stigter, J. Bezemer, K. de Groot, and P. Layrolle, "Incorporation of different antibiotics into carbonated hydroxyapatite coatings on titanium implants, release and antibiotic efficacy," J. Control. Release: Official Journal of the Controlled Release Society, vol. 99, pp. 127-37, 2004.

[50] P. Q. Ruhe, O. C. Boerman, F. G. Russel, P. H. Spauwen, A. G. Mikos, and J. A. Jansen, "Controlled release of rhBMP-2 loaded poly(dl-lactic-co-glycolic acid)/calcium phosphate cement composites in vivo," J. Control. Release : Official Journal of the Controlled Release Society, vol. 106, pp. 162-71, 2005.

[51] Y. Zheng, G. Wu, T. Liu, Y. Liu, and D. Wismeijer, "A Novel BMP2-Coprecipitated, Layer-by-Layer Assembled biomimetic calcium phosphate particle: a biodegradable and highly efficient osteoinducer," Clin. Implant Dent. Related Res., 2014, 16(5); pp. 643-54.

[52] H. Sterling, C. Saginario, and A. Vignery, "CD44 occupancy prevents macrophage multinucleation," J. Cell Bio., vol. 143, pp. 837-47, 1998.

[53] T. T. Hagi, G. Wu, Y. Liu, and E. B. Hunziker, "Cell-mediated BMP-2 liberation promotes bone formation in a mechanically unstable implant environment," Bone, vol. 46, pp. 1322-7, 2010.

[54] E. B. Hunziker, L. Enggist, A. Kuffer, D. Buser, and Y. Liu, "Osseointegration: the slow delivery of BMP-2 enhances osteoinductivity," Bone, vol. 51, pp. 98-106, 2012.

[55] W. Suchanek and M. Yoshimura, "Processing and properties of hydroxyapatite-based biomaterials for use as hard tissue replacement implants," J. Mater. Res., vol. 13, pp. 94-117, 1998.

[56] S. V. Dorozhkin, "Bioceramics of calcium orthophosphates," Biomaterials, vol. 31, pp. 1465-85, 2010.

[57] A. Okumura, M. Goto, T. Goto, M. Yoshinari, S. Masuko, T. Katsuki, and T. Tanaka, "Substrate affects the initial attachment and subsequent behavior of human osteoblastic cells (Saos-2)," Biomaterials, vol. 22, pp. 2263-71, 2001.

[58] G. E. Poinern, R. K. Brundavanam, N. Mondinos, and Z. T. Jiang, "Synthesis and characterisation of nanohydroxyapatite using an ultrasound assisted method," Ultrasonics Sonochem., vol. 16, pp. 469-74, 2009.

[59] Y. Taniguchi, T. Tamaki, H. Oura, H. Hashizume, and A. Minamide, "Sintered bone implantation for the treatment of benign bone tumours in the hand," J. Hand Surg., vol. 24, pp. 109-12, 1999.

[60] X. Lu and Y. Leng, "Theoretical analysis of calcium phosphate precipitation in simulated body fluid," Biomaterials, vol. 26, pp. 1097-108, 2005.

[61] D. A. Puleo and A. Nanci, "Understanding and controlling the bone-implant interface," Biomaterials, vol. 20, pp. 2311-21, 1999.

[62] M. J. Coathup, G. W. Blunn, N. Flynn, C. Williams, and N. P. Thomas, "A comparison of bone remodelling around hydroxyapatite-coated, porous-coated and grit-blasted hip replacements retrieved at post-mortem," J. Bone Joint Surg. (British Volume), vol. 83, pp. 118-23, 2001.

[63] T. W. Bauer, R. C. Geesink, R. Zimmerman, and J. T. McMahon, "Hydroxyapatite-coated femoral stems. Histological analysis of components retrieved at autopsy," J. Bone Joint Surg. (American Volume), vol. 73, pp. 1439-52, 1991

[64] M. S. Block, J. N. Kent, and J. F. Kay, "Evaluation of hydroxylapatite-coated titanium dental implants in dogs," Int. J. Oral Maxillofac. Surg. : Official Journal of the American Association of Oral and Maxillofacial Surgeons, vol. 45, pp. 601-7, 1987.

[65] M. S. Block, I. M. Finger, M. G. Fontenot, and J. N. Kent, "Loaded hydroxylapatite-coated and grit-blasted titanium implants in dogs," Int. J. Oral Maxillofac. Implants, vol. 4, pp. 219-25, 1989.

[66] L. B. Lum, O. R. Beirne, and D. A. Curtis, "Histologic evaluation of hydroxylapatite-coated versus uncoated titanium blade implants in delayed and immediately loaded applications," Int. J. Oral Maxillofac. Implants, vol. 6, pp. 456-62, 1991.

[67] K. de Groot, R. Geesink, C. P. Klein, and P. Serekian, "Plasma sprayed coatings of hydroxylapatite," J. Biomed. Mater. Res., vol. 21, pp. 1375-81, 1987.

[68] R. G. Geesink, "Hydroxyapatite-coated total hip prostheses. Twoyear clinical and roentgenographic results of 100 cases," Clin. Orthopaed. Related Res., pp. 39-58, 1990.

[69] M. A. Freeman, "Hydroxyapatite coating of prostheses," J. Bone Joint Surg. (British Volume), vol. 74, pp. 933-4, 1992.

[70] B. W. Johnson, "HA-coated dental implants: long-term consequences," J. Calif. Dent. Assoc., vol. 20, pp. 33-41, 1992.

[71] L. E. Wolinsky, P. M. de Camargo, J. C. Erard, and M. G. Newman, "A study of in vitro attachment of Streptococcus sanguis and Actinomyces viscosus to saliva-treated titanium," Int. J. Oral Maxillofac. Implants, vol. 4, pp. 27-31, 1989.

[72] S. A. Jovanovic, E. B. Kenney, F. A. Carranza, Jr., and K. Donath, "The regenerative potential of plaque-induced peri-implant bone defects treated by a submerged membrane technique: an experimental study," Int. J. Oral Maxillofac. Implants, vol. 8, pp. 13-8, 1993

[73] J. Abtahi, P. Tengvall, and P. Aspenberg, "A bisphosphonatecoating improves the fixation of metal implants in human bone. A randomized trial of dental implants," Bone, vol. 50, pp. 1148-51, 2012.

[74] U. Hansson, L. Ryd, and S. Toksvig-Larsen, "A randomised RSA study of Peri-Apatite HA coating of a total knee prosthesis," The Knee, vol. 15, pp. 211-6, 2008

[75] N. C. Geurs, R. L. Jeffcoat, E. A. McGlumphy, M. S. Reddy, and M. K. Jeffcoat, "Influence of implant geometry and surface characteristics on progressive osseointegration," Int. J. Oral Maxillofac. Implants, vol. 17, pp. 811-5, 2002.

[76] H. F. Morris, S. Ochi, J. R. Spray, and J. W. Olson, "Periodontaltype measurements associated with hydroxyapatite-coated and nonHA-coated implants: uncovering to 36 months," Ann. Periodontol., vol. 5, pp. 56-67, 2000.

[77] I. Landor, P. Vavrik, A. Sosna, D. Jahoda, H. Hahn, and M. Daniel, "Hydroxyapatite porous coating and the osteointegration of the total hip replacement," Arch. Ortho. P Trauma Surg., vol. 127, pp. 81-9, 2007

[78] M. Tanzer, J. Gollish, R. Leighton, K. Orrell, A. Giacchino, P. Welsh, B. Shea, and G. Wells, "The effect of adjuvant calcium 
phosphate coating on a porous-coated femoral stem," Clin. Orthop. Relat. Res., pp. 153-60, 2004.

[79] D. W. Johnston, D. M. Davies, L. A. Beaupre, and G. Lavoie, "Standard anatomical medullary locking (AML) versus tricalcium phosphate-coated AML femoral prostheses," Can. J. Surg., vol. 44, pp. 421-7, Dec 2001.

[80] U. Hansson, L. Ryd, and S. Toksvig-Larsen, "A randomised RSA study of Peri-Apatite HA coating of a total knee prosthesis," Knee, vol. 15 , pp. 211-6, 2008

[81] U. Lekholm, Zarb, G, "Tissue-integrated prosthesis: osseointegration in clinical dentistry," Quintessence, pp. 199-209, 1985.

[82] A. P. Saadoun and M. L. LeGall, "Clinical results and guidelines on Steri-Oss endosseous implants," Int. J. Periodont. Restorat. Dent., vol. 12, pp. 486-95, 1992.

[83] R. S. Truhlar, H. F. Morris, and S. Ochi, "Implant surface coating and bone quality-related survival outcomes through 36 months post-placement of root-form endosseous dental implants," Ann. Periodontol., vol. 5, pp. 109-8, Dec 2000.

[84] T. Albrektsson and L. Sennerby, "State of the art in oral implants," J. Clin. Periodontol., vol. 18, pp. 474-81, Jul 1991.

[85] B. W. Johnson, "HA-coated dental implants: long-term consequences," J. Calif. Dent. Assoc., vol. 20, pp. 33-41, 1992.

[86] C. M. Agrawal, J. Best, J. D. Heckman, and B. D. Boyan, "Protein release kinetics of a biodegradable implant for fracture nonunions," Biomaterials, vol. 16, pp. 1255-60, 1995.

[87] J. P. Fiorellini, D. Buser, E. Riley, and T. H. Howell, "Effect on bone healing of bone morphogenetic protein placed in combination with endosseous implants: a pilot study in beagle dogs," Int. J. Periodont. Restorat. Dent., vol. 21, pp. 41-7, 2001.

[88] I. Ono, H. Gunji, F. Kaneko, T. Saito, and Y. Kuboki, "Efficacy of hydroxyapatite ceramic as a carrier for recombinant human bone morphogenetic protein," J. Craniofac. Surg., vol. 6, pp. 238-44, 1995.

[89] A. H. Reddi and N. S. Cunningham, "Bone induction by osteogenin and bone morphogenetic proteins," Biomaterials, vol. 11, pp. 33-4, 1990.

[90] B. McKay and H. S. Sandhu, "Use of recombinant human bone morphogenetic protein-2 in spinal fusion applications," Spine, vol. 27, pp. S66-85, 2002.

[91] E. Carlisle and J. S. Fischgrund, "Bone morphogenetic proteins for spinal fusion," Spine J.: Official Journal of the North American Spine Society, vol. 5, pp. 240S-249S, 2005.

[92] S. A. Esenwein, S. Esenwein, G. Herr, G. Muhr, W. Kusswetter, and C. H. Hartwig, "[Osteogenetic activity of BMP-3-coated titanium specimens of different surface texture at the orthotopic implant bed of giant rabbits]," Der Chirurg; Zeitschrift fur alle Gebiete der operativen Medizen, vol. 72, pp. 1360-8, 2001.

[93] A. Piattelli, A. Scarano, M. Piattelli, and L. Calabrese, "Direct bone formation on sand-blasted titanium implants: an experimental study," Biomaterials, vol. 17, pp. 1015-8, 1996.

[94] H. M. Kim, F. Miyaji, T. Kokubo, and T. Nakamura, "Preparation of bioactive $\mathrm{Ti}$ and its alloys via simple chemical surface treatment," J. Biomed. Mater. Res., vol. 32, pp. 409-17, 1996.

[95] K. Endo, "Chemical modification of metallic implant surfaces with biofunctional proteins (Part 1). Molecular structure and biological activity of a modified NiTi alloy surface," Dent. Mater. J., vol. 14, pp. 185-98, 1995.

[96] H. Uludag, D. D'Augusta, R. Palmer, G. Timony, and J. Wozney, "Characterization of rhBMP-2 pharmacokinetics implanted with biomaterial carriers in the rat ectopic model," J. Biomed. Mater Res., vol. 46, pp. 193-202, 1999.

[97] H. Uludag, T. Gao, T. J. Porter, W. Friess, and J. M. Wozney, "Delivery systems for BMPs: factors contributing to protein retention at an application site," J. Bone Joint Surg. (Am. Vol.), vol. 83-A Suppl 1, pp. S128-35, 2001.

[98] D. Chen, M. Zhao, and G. R. Mundy, "Bone morphogenetic proteins," Growth Factors, vol. 22, pp. 233-41, Dec 2004.

[99] L. B. Shields, G. H. Raque, S. D. Glassman, M. Campbell, T. Vitaz, J. Harpring, and C. B. Shields, "Adverse effects associated with high-dose recombinant human bone morphogenetic protein-2 use in anterior cervical spine fusion," Spine, vol. 31, pp. 542-7, 2006.

[100] D. M. Smith, G. M. Cooper, M. P. Mooney, K. G. Marra, and J. E. Losee, "Bone morphogenetic protein 2 therapy for craniofacial surgery," J. Craniofac. Surg., vol. 19, pp. 1244-59, 2008.

Received: April 30, 2014

Revised: May 31, 2014

Accepted: August 30, 2014

(C) Lin et al.; Licensee Bentham Open.

This is an open access article licensed under the terms of the Creative Commons Attribution Non-Commercial License (http://creativecommons.org/licenses/by-nc/3.0/) which permits unrestricted, non-commercial use, distribution and reproduction in any medium, provided the work is properly cited. 